\title{
Isobutyryl-CoA Dehydrogenase Deficiency
}

National Cancer Institute

\section{Source}

National Cancer Institute. Isobutyryl-CoA Dehydrogenase Deficiency. NCI Thesaurus.

Code C129975.

An inherited condition caused by mutation(s) in the ACAD8 gene, encoding isobutyryl-CoA dehydrogenase, mitochondrial. It is characterized by decreased concentrations of carnitine in the blood, encephalopathy, dilated cardiomyopathy, and anemia. 